\title{
The effect of satiation following partial reinforcement
}

ROBERT B. HAAS, FREDERIC $M$. SHESSEL, HENRY S. WILLNER, and ROBERT A. RESCORLA, ' Yale University, New Haven, Conn. 06510

Rats deprived to $80 \%$ or $90 \%$ body weight received either $50 \%$ or $100 \%$ food reinforcement in a nuwway. They were then satiated and run on the same schedule. A history of partial reinforcement, or of more severe deprivation, produced faster response speeds during satiation. The greater resistance of partially reinforced responses to the decremental effects of satiation may be related to their high resistance to the effects of extinction and punishment.

It is well documented that partially reinforced instrumental responses are more resistant to the decremental effects of extinction than are continuously reinforced responses. Recently, Brown \& Wagner (1964) have found that partial reinforcement also attenuates the decremental effects of subsequently applied punishment. Following a frustration analysis, they suggest that the commonality of the aversive consequences of nonreinforcement during training and subsequent punishment mediates this attenuation. Amsel (1969) has discussed these results in terms of the general persistence of responding generated by partial reinforcement.

It is of interest to inquire about the generality of this persistence. Since two decremental operations, nonreinforcement and punishment, are less effective upon partially reinforced responses, it seems reasonable to ask if such responses would be more resistant to the effects of any operation normally decrementing responses. In particular, it would be of interest to investigate decremental operations not involving apparently aversive consequences attendant upon making the response. Accordingly, the present study examined the relative effectiveness of satiation in depressing partially and continuously reinforced responses.

\section{SUBJECTS AND APPARATUS}

The Ss were 32 male Sprague-Dawley rats, 100 days old at the beginning of the experiment. Two animals became ill during the experiment and were discarded. The apparatus was a conventional straight alley, $72 \times 4 \times 4$ in. The sides of the runway were wood, painted gray. The top and floor were $1 / 2$-in. hardware cloth. Guillotine doors separated the 9-in. starting and goal compartments from the remainder of the alley. A $2 \times 1$ in. trough placed at the end of the goalbox served as the food cup. Photobeams, located $7 \mathrm{in}$. into the alley from the startbox door and 9 in. into the goalbox, permitted the measurement of starting and running speeds. The room illumination consisted of overhead lights; a constant white noise was used to mask extraneous sounds.

\section{PROCEDURE Pretraining}

Several days prior to training, the Ss were handled and placed on a deprivation schedule. Half the Ss were reduced to $80 \%$ and half to $90 \%$ of their normal body weights. Two days prior to acquisition of the running response, all $S s$ were habituated by placement in the alley with several $45 \cdot \mathrm{mg}$ food pellets in the food cup. Acquisition

Each $S$ received 10 trials per day with an intertrial interval determined by the time required to run three other Ss. A trial was begun by placing $S$ in the startbox, facing away from the door; when $S$ turned and faced the door, it was opened, allowing $S$ to traverse the runway. When $S$ entered the goalbox, the second guillotine door was lowered and $\mathrm{S}$ was removed approximately $3 \mathrm{sec}$ later. On the first day of acquisition, the first five trials were rewarded for all Ss; thereafter, differential treatment was begun. Half of each of the body-weight groups received $100 \%$ reinforcement and half, $50 \%$ reinforcement, thus generating four groups. For the $50 \%$ groups, the daily sequence of reinforced and nonreinforced trials was changed systematically to reduce sequential dependencies. For all animals, the reward was three 45 -mg food pellets. Training continued for a total of 70 trials. Satiation

Following the final acquisition day, all Ss were placed on an ad lib feeding schedule. For the remainder of the experiment, they were given free access to the usual laboratory chow, moistened powdered chow, and a dish of the reward pellets used in the alley. After $48 \mathrm{~h}$ of initial satiation, training identical to that of the acquisition phase was resumed in the alley for 6 days. For $30 \mathrm{~min}$ prior to each daily session, $S$ was placed in a cage other than his home cage and given additional 45-mg pellets. During this phase, reward continued to be administered in the goalbox on the same schedule as in acquisition. If $S$ did not leave the startbox within $60 \mathrm{sec}$ or traverse the alley within $120 \mathrm{sec}$, it was removed from the apparatus and scores of 60 and $120 \mathrm{sec}$ were recorded for that trial.

\section{RESULTS}

Figure 1 shows the starting speeds in blocks of five trials for the final acquisition session and the six satiation sessions. The data are recorded in terms of the mean across Ss of each animal's median starting speed for each five-trial block. Since starting and running speeds gave similar results, only the former will be reported here.

Although Fig. 1 indicates that the $90 \%$ body-weight groups ran more slowly than did the $80 \%$ groups on the final presatiation day, the difference fell short of conventional reliability levels $(F=3.63$, $\mathrm{df}=1 / 26, .05<\mathrm{p}<.10$ ). Neither the effect of percentage reinforcement nor the interaction approached significance.

With the institution of ad lib feeding, all starting speeds dropped sharply; however, the magnitude of the decrement was a function of the treatment prior to satiation. The groups with a history of $80 \%$ deprivation exhibited reliably faster starting speeds than did those formerly receiving $90 \%$ deprivation $\quad(F=11.69$, $\mathrm{df}=1 / 26, \mathrm{p}<.01)$. More interestingly, the groups with a history of $50 \%$ reinforcement showed faster starting speeds during satiation than did those with a history of continuous reinforcement

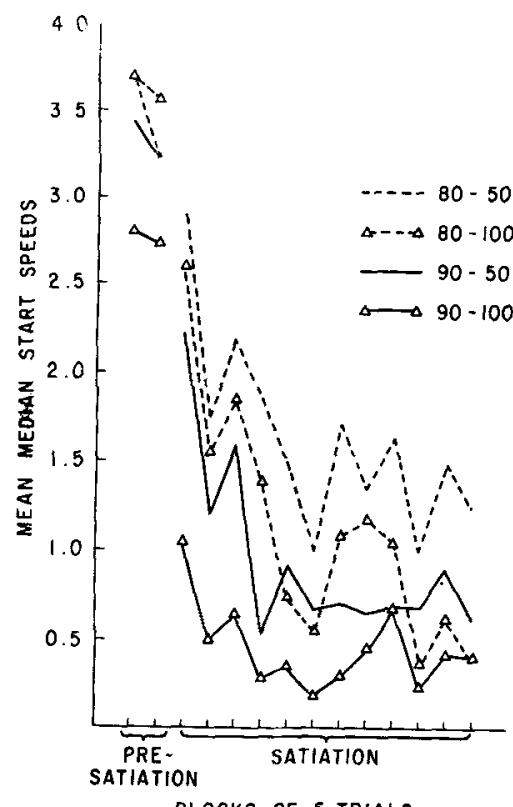

Fig. 1. Mean-median starting speed over blocks of five trials during the final acquisition day and the 6 days of satiation. 
$(F=6.44, \quad$ df $=1 / 26, \quad p<.05)$. The interaction was not reliable, indicating that the two effects were relatively independent; for both body weights, the $50 \%$ animals ran faster during satiation than did the $100 \%$ animals.

Figure 1 also indicates that starting speeds were not constant during the satiation phase $(F=12.17, \mathrm{df}=11 / 286$, $\mathrm{p}<.01)$. This change over trials occurs primarily during the first two satiation sessions. However, the decrement does not seem attributable to increasingly effective satiation since it occurred largely within each session.

During the satiation phase, food reward was continued in the goalbox. Despite free access to such a reward immediately prior to each daily session, Ss continued to consume the goalbox reward with infrequent exceptions.

\section{DISCUSSION}

The finding of primary interest in this study is that partially reinforced animals are more resistant to the decremental effects of satiation than are continuously reinforced animals. Linton \& Miller (1951), in an experiment similar to ours, also found a tendency for greater persistence of intermittently reinforced animals when satiated. Since the difference in their experiment was not statistically reliable, they concluded that percentage reinforcement had no effect upon subsequent behavior under satiation; however, reliable differences among their groups prior to satiation make interpretation of their results difficult.

The present findings, taken together with the higher resistance of partially reinforced animals to the effects of extinction and punishment, suggest the possibility that intermittent reinforcement yields a response of greater stability in the face of any interfering events. In addition to whatever other effects partial reinforcement may have, it may generate greater "response strength." Should this prove so, it would have implications for theories of the partial-reinforcement extinction effect. For instance, it is difficult to argue that the resistance to the effects of satiation in partially reinforced animals is mediated by the similarity in the aversive consequences of nonreinforcement and satiation.

The faster starting speeds of animals with a history of more severe deprivation may be interpreted in terms of the effects of drive upon amount of learning. However, some caution should be exercised in making this interpretation. During satiation, the average body weight of the $80 \%$ groups remained below that of the $90 \%$ groups, suggesting that satiation may have been less complete for those animals.

\section{REFERENCES}

AMSEL, A. Behavioral habjtuation, counterconditioning, and persistence. Presented at a conference on classical conditioning, McMaster University, May 1969. BROWN, R. T., \& WAGNER, A. R. Resistance to punishment and extinction following training with shock or nonreinforcement. Journal of Experimental Psychology, 1964, 68, 503-507. LINTON, H. B., \& MILLER, N. E. The effect of partial reinforcement on behavior during satiation. Joumal of Comparative \& Physiological Psychology, 1951, 44, 142-148. NOTE

1. This research was supported in part by NSF Grant GB-6493 and in part by funds from Yale University. The first three authors were undergraduates supervised by the last author. Reprint requests should be sent to: Robert $A$. Rescorla, Department of Psychology, Yale University, 333 Cedar St., New Haven, Conn. 06510.

\section{Predictability of schedule-induced drink durations}

\section{J. D. KEEHN and V. A. COLOTLA, York University and Addiction Research Foundation, Toronto, Ont., Canada}

Four white rats were reinforced with food for bar-pressing on fixed- and variable-interval schedules of 1 and $2 \mathrm{~min}$. All four developed polydipsia. Except for some disruption following schedule changes from variable to fixed intervals, licking almost invariably followed reinforcement. Cumulative plots of post-pellet drink durations closely approximated straight lines, showing drink durations to be relatively constant.

When food and water are freely available, the durations and distributions of eating and drinking by rats appear to be unpredictable (Premack, 1965). It is possible to alter average durations of bursts of eating (Premack, 1965) and drinking (Davis \& Keehn, 1959) by manipulating the quality of the substance offered for ingestion, but the unpredictability of the durations of individual consummatory response bursts remains unaffected. A way of affecting the predictability of individual bursts of licking without constraining drinking by either deprivation or contingencies may be to schedule small meals intermittently. Such a procedure produces polydipsia (Falk, 1961), in which unscheduled and unconstrained drinking typically follows food pellet consumption. There are indications (e.g., Falk, 1966) that the durations of drinks of this kind are relatively constant. Further evidence that induced postpellet drink durations may be predictable is reported below.

$$
\text { SUBJECTS }
$$

The Ss were four experimentally naive laboratory-bred hooded rats. They were about 150 days old at the beginning of the experiment and were maintained at $85 \%$ of their free-feeding body weights throughout the experiment. They were individually housed, and water was continuously available.

\section{APPARATUS}

Two Grason-Stadler two-bar rat chambers, Type E3125B, were employed. In each, the left-hand bar was removed and its opening covered with a metal plate flush with the wall. A dead weight of $20 \mathrm{~g}$ on the right-hand bar activated relay programming and recording equipment. Reinforcements were $45-\mathrm{mg}$ Noyes rat pellets delivered by a Gerbrands pellet dispenser. A Grason-Stadler drinkometer was used to monitor licks at the glass drinking spout of a water bottle clipped to the outside of the chamber door. Licks and bar-presses were recorded by Gerbrands cumulative recorders. The animal chambers were enclosed by ventilated chests in a closet of the room containing the cumulative recorders and electromagnetic programming apparatus.

Table 1

Median Water Intakes (ml Per 3 H Session)

\begin{tabular}{lrrrrr}
\hline \multicolumn{2}{l}{ Schedule* Sessions } & MD3 & MD4 & MD7 & MD8 \\
\hline VI & $1-23$ & 48 & 62 & 37 & 37 \\
FI** & $24-33$ & $35 * * *$ & 50 & 18 & 26 \\
VI** & $34-38$ & 34 & 46 & 41 & 37 \\
VI & $39-44$ & 42 & 58 & 59 & 46 \\
FI & $45-54$ & 38 & 44 & 56 & 45 \\
VI & $55-60$ & 42 & 72 & 69 & 45 \\
\hline
\end{tabular}

* Intervals were 1 min for $M D 3, M D 4, M D 7$; $2 \min$ for $M D 8$

** Sessions began with 50 crf in these periods *** The schedule for MD3 was VI in this period 